\title{
Thiazide-Induced Hyponatremia
}

\section{Kyu Sig Hwang, M.D. \\ Gheun-Ho Kim, M.D.}

Department of Internal Medicine, Hanyang

University College of Medicine, Seoul, Korea
Received : May 4, 2010. Accepted: May 24, 2010

Corresponding author: Gheun-Ho Kim, M.D.

Department of Internal Medicine, Hanyang University

College of Medicine, 17 Haengdang-dong, Seongdong-

gu, Seoul, 133-792, Korea

Tel: +82-2-2290-8318, Fax: +82-2-2298-9183

E-mail: kimgh@hanyang.ac.kr
The importance of thiazide-induced hyponatremia $(\mathrm{TIH})$ is reemerging because thiazide diuretic prescription seems to be increasing after the guidelines recommending thiazides as first-line treatment of essential hypertension have been introduced. Thiazide diuretics act by inhibiting reabsorption of $\mathrm{Na}^{+}$and $\mathrm{Cl}^{-}$from the distal convoluted tubule by blocking the thiazide-sensitive $\mathrm{Na}^{+} / \mathrm{Cl}^{-}$ cotransporter. Thus, they inhibit electrolyte transport in the diluting segment and may impair urinary dilution in some vulnerable groups. Risk factors predisposing to TIH are old age, women, reduced body masses, and concurrent use of other medications that impair water excretion. While taking thiazides, the elderly may have a greater defect in water excretion after a water load compared with young subjects. Hyponatremia is usually induced within 2 weeks of starting the thiazide diuretic, but it can occur any time during thiazide therapy when subsequent contributory factors are complicated, such as reduction of renal function with aging, ingestion of other drugs that affect free water clearance, or changes in water or sodium intake. While some patients are volume depleted on presentation, most appear euvolemic. Notably serum levels of uric acid, creatinine and urea nitrogen are usually normal or low, suggestive of syndrome of inappropriate secretion of antidiuretic hormone. Despite numerous studies, the pathophysiological mechanisms underlying $\mathrm{TIH}$ are unclear. Although the traditional view is that diuretic-induced sodium or volume loss results in vasopressin-induced water retention, the following 3 main factors are implicated in TIH: stimulation of vasopressin secretion, reduced free-water clearance, and increased water intake. These factors will be discussed in this review.

Key Words: hyponatremia; thiazides; water; diuretics; vasopressins

\section{Introduction}

Thiazide diuretics include all diuretics believed to have a primary action to inhibit $\mathrm{NaCl}$ reabsorption in the distal convoluted tubule (Table 1 ) and have been used in the management of hypertension for over 50 years ${ }^{1,}$ 2). These agents decrease blood pressure (BP) when administered as monotherapy, enhance the efficacy of other antihypertensive agents, and reduce hypertensionrelated morbidity and mortality. However, the use of thiazide diuretics is often limited by concerns about some metabolic change, e.g., hyponatremia, hypokalemia and insulin resistance ${ }^{3)}$.

Hyponatremia is an occasional but potentially fatal complication of diuretic therapy. The first detailed description of diuretic-induced hyponatremia was published over 35 years ago ${ }^{4)}$. Since that time, numerous additional cases have been reported. Thiazides are a common cause of severe hyponatremia in hospitalized patients ${ }^{5)}$ and are associated with high morbidity and 
Table 1. Thiazide Diuretics

\begin{tabular}{l}
\hline Thiazide-type (presence of a benzothiadiazine structure) \\
Chlorothiazide \\
Hydrochlorothiazide \\
Methylchlothiazide \\
Polythiazide \\
Bendroflumethiazide \\
Thiaizde-like (mechanism of action similar to that of thiazide-type \\
diuretics) \\
Metolazone \\
Chlorthalidone \\
Indapamide
\end{tabular}

mortality $^{6,7)}$.

Virtually all cases of severe diuretic-induced hyponatremia have been due to a thiazide-type diuretic ${ }^{6-12)}$. In contrast, loop diuretics are implicated much less commonly $^{7}$. This observation is probably derived from the different nephronal sites of action of these two classes of diuretics. Thiazide diuretics inhibit $\mathrm{NaCl}$ reabsorption in the distal convoluted tubule, the main diluting site of the nephron. Thus, thiazide diuretics interfere with maximum dilution of urine because sodium $\left(\mathrm{Na}^{+}\right)$ excretion is increased along with diminished free-water excretion $^{13}{ }^{14)}$. On the other hand, loop diuretics inhibit $\mathrm{NaCl}$ reabsorption in the thick ascending limb of the loop of Henle. The reabsorption of $\mathrm{NaCl}$ without water in the medullary thick ascending limb is normally the primary step in the generation of the hypertonicity in the medullary interstitium, and loop diuretics mainly impair urinary concentration and limit water retention and development of hyponatremia ${ }^{15)}$.

Although thiazide diuretics are frequently recommended as the first-line anti-hypertensive according to the practice guidelines and results of the major clinical trials such as the Antihypertensive and Lipid-Lowering Treatment to Prevent Heart Attack Trial (ALLHAT) ${ }^{16-18)}$, the mechanism and optimal treatment of thiaizde-induced hyponatremia $(\mathrm{TIH})$ remain unclear. In this review, we will explore the pathogenesis, discuss the clinical features, and suggest an approach to the treatment of $\mathrm{TIH}$.

\section{Epidemiology of TIH}

Electrolyte disturbance is common after administration of thiazide diuretics, and hyponatremia is a typical complication with an estimated incidence of $11 \%$ in one series of 114 geriatric patients ${ }^{19)}$. In the Systolic Hypertension in the Elderly Program (SHEP), which focused on older patients, hyponatremia was observed in $4.1 \%$ of patients treated with chlorthalidone versus $1.3 \%$ in the control group $^{20)}$. Thirty percent of patients were receiving 12.5 $\mathrm{mg} /$ day of chlorthalidone, and $60 \%$ were receiving 25 $\mathrm{mg} / \mathrm{day}^{20)}$. In another study on elderly patients, diureticinduced hyponatremia was seen in $17 \%$ and hypokalemia in $6.6 \%{ }^{21}$. Fifty three percent of patients were receiving a thiazide diuretic and 24\% a loop diuretic ${ }^{21)}$. In patients with $\mathrm{TIH}$, an average daily hydrochlorothiazide dose of $35 \mathrm{mg}$ has been reported, with $44 \%$ of patients having received $\geq 50 \mathrm{mg}^{22)}$. On the other hand, in $10 \%$ of the cases with TIH the dose was only $12.5 \mathrm{mg}^{23}$. Considering the high prevalence of hypertension in the elderly and the routine use of thiazide diuretics to treat it, TIH is clearly a prevalent problem.

The question arises as to whether a certain subgroup of patients is susceptible to this adverse effect of thiazides. The risk factors of TIH are old age, women, reduced body mass $^{7,9,13,14,22,24)}$, and concurrent use of other medications that impair water excretion ${ }^{13,25)}$. As shown in Table 2 which was obtained by the recent nephrology consultation in our hospital, old women are clearly predisposed to TIH.

According to the experiment done by Clark et al. ${ }^{13)}$, healthy elderly subjects do not excrete free water as efficiently as younger ones do. In particular, elderly subjects with a previous history of TIH have impaired urinary dilution capacity, and hence, increased susceptibility to TIH. Among the explanations, blunted prostaglandin synthesis is an attractive possibility ${ }^{25)}$, and could result from aging or propensity among the elderly for polypharmacy, including non-steroidal anti-inflammatory agents.

The reason why individuals with reduced body mass are more prone to complications from diuretics remains 
puzzling. Plasma $\mathrm{Na}^{+}$level is determined by the ratio between the amount of exchangeable $\mathrm{Na}^{+}$and potassium $\left(\mathrm{K}^{+}\right)$and the total body water ${ }^{26}$. Thus, it is conceivable that $\mathrm{Na}^{+}$concentration might change to a greater degree in a subject with smaller body size, and hence less total body water. Besides, small body mass or muscle wasting might also signify underlying illness ${ }^{27}$.

Numerous case reports have indicated that hypertensive women are particularly at risk to develop hyponatremia ${ }^{7}$ $9,13,14,22,24)$. The reason that women are more susceptible to the effects of thiazide diuretics than men is unknown. Women probably drink more than men to compensate for the diuretic and therefore develop more dilutional hyponatremia ${ }^{28)}$, and hypertensive women may be more often treated with diuretics than hypertensive men ${ }^{29)}$. Moreover, women may be more symptomatic than men at comparable serum $\mathrm{Na}^{+}$levels and therefore may be diagnosed more often than men ${ }^{30)}$.

\section{Clinical characteristics of TIH}

The clinical manifestations of TIH are similar to those due to other causes of hyponatremia. TIH can develop acutely or gradually. It can range from mild to severe and from asymptomatic to symptomatic. One of the most remarkable features of $\mathrm{TIH}$ is the rapidity with which it can occur. In susceptible individuals, the serum $\mathrm{Na}^{+}$may fall within hours of administration ${ }^{8)}$, and severe hyponatremia can develop within less than 2 days $^{7}{ }^{74}$. In most reported cases $(50 \%$ to $90 \%)$ the duration of thiazide use was less than 2 weeks ${ }^{7,8,14,22)}$. However it can occur any time during thiazide therapy when sub-sequent contributory factors are complicated such as old age, increased water intake, low salt intake ${ }^{7,9,13,14,22,24)}$, and concurrent use of other medications that impair water excretion ${ }^{13,25)}$.

Mild hyponatremia, with serum $\mathrm{Na}^{+}$concentration in the range of 125 to $132 \mathrm{mEq} / \mathrm{L}$, is usually asymptomatic, although vague symptoms such as fatigue or nausea are possible $^{3)}$. More severe hyponatremia, as reported in patients who required hospitalization, can be asymptomatic or associated with symptoms including weakness, vomiting, nausea, confusion, dizziness, abdominal pain, and manifestations as serious as lethargy, seizures, and $\operatorname{coma}^{11,22)}$.

The volume status of TIH may be variable. While some patients are volume depleted on presentation, most appear to be euvolemic ${ }^{10,14,31,32)}$. Reduced free-water clearance can explain why many patients with TIH behave as if they are volume expanded; the body weight may initially increase ${ }^{8)}$. In patients with TIH, blood urea nitrogen (BUN) and plasma creatinine concentration are generally low-normal ${ }^{10}$ 33), and hypouricemia due to enhanced urinary uric acid excretion may be present ${ }^{32,33)}$. All of these findings are similar to those in the syndrome of inappropriate antidiuretic hormone secretion (SIADH), which is also associated with initial volume expansion. The laboratory data from our TIH patients are also compatible with those of SIADH (Table 2), similarly to reports from other studies $^{8-11,13)}$. According to Sonnenblick et al. ${ }^{32)}$, elevated fractional uric acid clearance and low serum uric acid level were useful to determine that TIH was more favored than furosemide-induced hyponatremia.

\section{Pathogenesis of TIH}

Despite numerous studies, the pathophysiological mechanisms underlying TIH are unclear. Although the traditional view is that diuretic-induced $\mathrm{Na}^{+}$or volume

Table 2. Data from Patients $(n=14)$ with Hydrochlorothiazide-Induced Hyponatremia

\begin{tabular}{lc}
\hline Gender $(\mathrm{M} / \mathrm{F})$ & $0 / 14$ \\
Age (years) & $78 \pm 6(62-87)$ \\
Serum $\mathrm{Na}^{+}(\mathrm{mEq} / \mathrm{L})$ & $118 \pm 6(106-128)$ \\
Serum osmolality $(\mathrm{mOsm} / \mathrm{kg})$ & $241 \pm 11(221-256)$ \\
Serum $\mathrm{K}^{+}(\mathrm{mEq} / \mathrm{L})$ & $3.5 \pm 0.6(2.2-4.1)$ \\
Serum $\mathrm{Cl}^{-}(\mathrm{mEq} / \mathrm{L})$ & $82 \pm 8(70-96)$ \\
Serum total CO $(\mathrm{mEq} / \mathrm{L})$ & $23.4 \pm 2.8(20.1-28.4)$ \\
Urine osmolality $(\mathrm{mOsm} / \mathrm{kg})$ & $391 \pm 119(215-584)$ \\
Urine $\mathrm{Na}^{+}(\mathrm{mEq} / \mathrm{L})$ & $91 \pm 51(15-194)$ \\
BUN $(\mathrm{mg} / \mathrm{dL})$ & $12 \pm 4(7-18)$ \\
Serum creatinine $(\mathrm{mg} / \mathrm{dL})$ & $0.7 \pm 0.2(0.4-1.1)$ \\
Serum uric acid $(\mathrm{mg} / \mathrm{dL})$ & $3.1 \pm 1.0(1.5-4.9)$ \\
\hline Continuous parameters are described as mean $\pm \mathrm{SD} \mathrm{(range).} \mathrm{BUN,} \mathrm{blood}$ \\
urea nitrogen.
\end{tabular}

$78 \pm 6(62-87)$

$3.4+2.8(20.1-28.4)$

$0.7 \pm 0.2(0.4-1.1)$

$3.1 \pm 1.0(1.5-4.9)$ 
Table 3. Contributory Factors for Thiazide-Induced Hyponatremia

1. Excess free-water intake
Increased water intake
Low salt intake
2. Reduced free-water clearance
Reduced renal capacity to excrete free-water, usually age-related
Stimulation of vasopressin release
Ingestion of other drugs that impair free-water clearance
3. Renal $\mathrm{Na}^{+}$and/or $\mathrm{K}^{+}$loss.

loss results in vasopressin-induced water retention, the following 3 main factors are implicated in TIH: increased water intake, reduced free-water clearance and renal $\mathrm{Na}^{+}$ and/or $\mathrm{K}^{+}$loss (Table 3).

There is evidence that water intake is maintained or increased in many patients with $\mathrm{TIH}^{6,8,27)}$. Friedman et al. ${ }^{8)}$ showed that within 6 hours of ingesting a single hydrochlorothiazide-amiloride tablet, previously affected patients had a small rise in urine osmolality and a fall in serum $\mathrm{Na}^{+}$of $5.5 \mathrm{mEq} / \mathrm{L}$ in association with a small gain in weight; controls had only a slight fall in serum $\mathrm{Na}^{+}$, and their mean weight fell. Although water intake was not measured, the authors suggested that thiazides might cause polydipsia, which, when combined with the renal effects, results in expansion of total body water and development of hyponatremia. Stimulation of water intake would not only help defend the extracellular volume, but would also explain why thiazides are one of the most common causes of severe hyponatremia.

Increased water intake would not lead to hyponatremia unless impairment in water excretion exists. While thiazide diuretics do not inhibit concentrating ability, they do impair diluting ability in several ways ${ }^{15,26,34)}$. As mentioned above, they inhibit electrolyte transport at the cortical diluting sites, thereby raising the minimum urinary osmolality ${ }^{34-36)}$. Diuretics may also reduce glomerular filtration rate and enhance reabsorption of $\mathrm{Na}^{+}$and water in the proximal nephron, diminishing fluid delivery to the distal diluting sites ${ }^{35)}$. Thus, water can be retained independent of serum osmolality. Besides, thiazide-induced volume depletion probably contributes to the genesis of $\mathrm{TIH}$ in some cases. Hypovolemia may stimulate the release of vasopressin because non-osmotic vasopressin secretion is very common in normovolemic and hypovolemic types of hyponatremia ${ }^{31)}$.

Thiazides may directly affect water permeability in the collecting duct epithelia ${ }^{37)}$. A previous in vitro microperfusion study showed that hydrochlorothiazide enhanced water absorption in the inner medullary collecting duct from normal rats and Brattleboro rats as well $^{38)}$. Consistent with this, Kim et al. reported that the paradoxical antidiuresis induced by hydrochlorothiazide in nephrogenic diabetes insipidus was associated with upregulation of aquaporin-2 in the collecting duct ${ }^{39}$.

There is much evidence that patients with TIH are electrolyte-deficient. First, virtually all relevant studies have found that during the development of TIH, $\mathrm{Na}^{+}$ balance is negative ${ }^{4,6,10)}$. Fuisz et al. argued that changes in external $\mathrm{Na}^{+}$and water balance did not completely account for the fall in serum $\mathrm{Na}^{+4}$. Furthermore, chlorothiazide induced hyponatremia in their patients despite $\mathrm{Na}^{+}$supplementation and positive $\mathrm{Na}^{+}$balance. These observations led the authors to conclude that a shift of $\mathrm{Na}^{+}$into the intracellular space contributed to the pathogenesis of hyponatremia. Second, once diuretics are withdrawn, urinary $\mathrm{Na}^{+}$excretion falls to very low levels ${ }^{4,10)}$. Third, many of these patients are hypokalemic ${ }^{4,}$ ${ }^{6,10)}$. Fichman et al. ${ }^{10)}$ emphasized the importance of $\mathrm{K}^{+}$ depletion in TIH. The great majority of their 25 patients was hypokalemic, and hyponatremia was corrected in 4 of them by $\mathrm{K}^{+}$repletion despite continued diuretic use and $\mathrm{Na}^{+}$restriction. These investigators argued that $\mathrm{K}^{+}$ depletion predisposes the patients to hyponatremia because the serum $\mathrm{Na}^{+}$concentration is dependent upon the ratio of the sum of exchangeable $\mathrm{Na}^{+}$and $\mathrm{K}^{+}$to total body water. They also speculated that $\mathrm{K}^{+}$depletion might cause a shift of $\mathrm{Na}^{+}$into the intracellular space, thereby further compromising the extracellular volume and stimulating vasopressin release. $\mathrm{Na}^{+}$and/or $\mathrm{K}^{+}$depletion alone would not be expected to cause marked hyponatremia because water excretion normally increases as the serum $\mathrm{Na}^{+}$ concentration falls. However, because thiazides interfere with renal water excretion, they impair this normal 
osmoregulatory response. Thus, as in most patients with hyponatremia, urine osmolality is inappropriately high relative to the osmolality of plasma and often exceeds it ${ }^{4,6}$, $10,31,32)$.

Several drugs increase the likelihood of developing TIH. Nonsteroidal anti-inflammatory drugs, through prostaglandin inhibition, decrease free-water clearance ${ }^{13,}$ ${ }^{25)}$. Drugs such as chlorpropamide or selective serotonin reuptake inhibitors may be associated with $\mathrm{SIADH}^{3)}$. Polydipsia caused by psychotropic medications also predisposes to $\mathrm{TIH}^{3)}$.

\section{Management of $\mathrm{TIH}$}

The acute management of TIH is more determined by the presence or absence of neurologic symptoms than by the $\mathrm{Na}^{+}$level per se. Treatment consists of discontinuing thiazides, regular diet (usually supplemented with $\mathrm{K}^{+}$) restricting water, administration of furosemide and either isotonic saline or, if the hyponatremia is severe or symptomatic, hypertonic saline.

In patients with hypovolemic $\mathrm{TIH}$, in whom vasopressin secretion stimulated by hypovolemia contributes to the inability to excrete free water, normal saline infusion is appropriate because it will restore volume and suppress vasopressin release. In patients with severe manifestations such as seizures or coma, initiation of treatment with hypertonic saline to assure rapid onset of response is recommended $^{3,16)}$. We treated our patients with TIH using

Table 4. Comparison of Biochemical Data According to Saline Preparations Used in Treatment of Thiazide-Induced Hyponatremia

\begin{tabular}{lccc}
\hline & $\begin{array}{c}\text { Hypertonic saline } \\
(\mathrm{n}=5)\end{array}$ & $\begin{array}{c}\text { Isotonic saline } \\
(\mathrm{n}=9)\end{array}$ & $P^{*}$ \\
\hline Serum $\mathrm{Na}^{+}(\mathrm{mEq} / \mathrm{L})$ & $112 \pm 4$ & $121 \pm 5$ & 0.009 \\
Serum $\mathrm{K}^{+}(\mathrm{mEq} / \mathrm{L})$ & $3.5 \pm 0.4$ & $3.5 \pm 0.7$ & $\mathrm{NS}$ \\
Serum total $\mathrm{CO}_{2}(\mathrm{mEq} / \mathrm{L})$ & $21.9 \pm 1.6$ & $24.2 \pm 3.1$ & $\mathrm{NS}$ \\
BUN $(\mathrm{mg} / \mathrm{dL})$ & $12 \pm 4$ & $12 \pm 4$ & $\mathrm{NS}$ \\
Uric acid $(\mathrm{mg} / \mathrm{dL})$ & $3.4 \pm 1.0$ & $2.9 \pm 1.0$ & $\mathrm{NS}$ \\
Urine osmolality $(\mathrm{mOsm} / \mathrm{kg})$ & $478 \pm 117$ & $343 \pm 94$ & 0.053 \\
Urine $\mathrm{Na}^{+}(\mathrm{mEq} / \mathrm{L})$ & $96 \pm 63$ & $88 \pm 47$ & $\mathrm{NS}$ \\
\hline
\end{tabular}

Data are presented as mean \pm SD.

BUN, blood urea nitrogen; NS, not significant.

* Comparison was performed by Mann-Whitney U test. either isotonic or 3\% hypertonic saline (Table 4). The data suggest that the severity of hyponatremia might influence the choice between isotonic and hypertonic saline.

In patients with euvolemia or hypervolemia-associated hyponatremia, who tend to have lower serum levels of uric acid, BUN, and creatinine, normal saline will not restore free-water clearance or serum $\mathrm{Na}^{+}$concentration. In such patients, hypertonic saline will predictably raise serum $\mathrm{Na}^{+}$concentration and is preferable. Administration of furosemide in addition to the hypertonic saline can increase free-water clearance and thus hasten the increase of the serum $\mathrm{Na}^{+}$concentration while avoiding volume overload $^{5}$.

In asymptomatic or minimally symptomatic patients, stopping the offending diuretic and restricting water intake to $<1 \mathrm{~L} /$ day is usually all that is needed. Normal saline is not needed unless correction of volume depletion is indicated. Increasing oral salt intake in combination with fluid restriction can increase serum $\mathrm{Na}^{+}$concentration ${ }^{3)}$.

\section{Prevention of TIH}

How can TIH be prevented? There are no guidelines regarding measures to prevent TIH. The first step in prevention of TIH is awareness that it can happen, particularly in the elderly, female, or small individuals. In susceptible individuals, the serum $\mathrm{Na}^{+}$may fall in hours of diuretic ingestion, and severe hyponatremia can develop within 2 days $^{7,14)}$. Therefore in susceptible patients, serum $\mathrm{Na}^{+}$should be measured within one day after beginning therapy. If the serum $\mathrm{Na}^{+}$level falls more than a few $\mathrm{mEq} / \mathrm{L}$, the diuretic should be stopped. If there is little or no change in the serum $\mathrm{Na}^{+}$, it should be rechecked 1-2 days later to be sure the level is stable ${ }^{14)}$.

Identifying patients with excessive fluid intake and counseling them to reduce their intake would be extremely helpful and cost-effective. When prescribing thiazides, low doses should be used ${ }^{3)}$. Only $10 \%$ of TIH cases occur at low dosage ${ }^{19,20,22)}$. A lower dose would increase the ability to excrete free-water, would reduce the hypovolemic 
stimulus for vasopressin secretion, and can correct borderline hyponatremia in many cases ${ }^{3)}$. Even patients who have done well on chronic thiazide therapy may develop severe hyponatremia if water intake increases. Therefore, all patients using these drugs should be educated about the danger of drinking excessive water ${ }^{3,14)}$.

\section{Acknoledgements}

This study was supported by a grant from Fresenius Medical Care Korea, 2009.

\section{References}

1) Freis ED, Wanko A, Wilson IM, Parrish AE: Treatment of essential hypertension with chlorothiazide (diuril); its use alone and combined with other antihypertensive agents. J Am Med Assoc 166:137-140, 1958

2) Moser M, Macaulay AI: Chlorothiazide as an adjunct in the treatment of essential hypertension. Am J Cardiol 3:214-219, 1959

3) Mann SJ: The silent epidemic of thiazide-induced hyponatremia. J Clin Hypertens (Greenwich) 10:477-484, 2008

4) Fuisz RE, Lauler DP, Cohen P: Diuretic-induced hyponatremia and sustained antidiuresis. Am J Med 33:783-791, 1962

5) Adrogue HJ, Madias NE: Hyponatremia. N Engl J Med 342:1581-1589, 2000

6) Ashraf N, Locksley R, Arieff AI: Thiazide-induced hyponatremia associated with death or neurologic damage in outpatients. Am J Med 70:1163-1168, 1981

7) Sonnenblick M, Friedlander Y, Rosin AJ: Diuretic-induced severe hyponatremia. Review and analysis of 129 reported patients. Chest 103:601-606, 1993

8) Friedman E, Shadel M, Halkin H, Farfel Z: Thiazide-induced hyponatremia. Reproducibility by single dose rechallenge and an analysis of pathogenesis. Ann Intern Med 110:24-30, 1989

9) Chow KM, Szeto CC, Wong TY, Leung CB, Li PK: Risk factors for thiazide-induced hyponatraemia. QJM 96:911-917, 2003

10) Fichman MP, Vorherr H, Kleeman CR, Telfer N: Diureticinduced hyponatremia. Ann Intern Med 75:853-863, 1971

11) Chow KM, Kwan BC, Szeto CC: Clinical studies of thiazideinduced hyponatremia. J Natl Med Assoc 96:1305-1308, 2004

12) Ernst ME, Moser M: Use of diuretics in patients with hypertension. N Engl J Med 361:2153-2164, 2009

13) Clark BA, Shannon RP, Rosa RM, Epstein FH: Increased sus- ceptibility to thiazide-induced hyponatremia in the elderly. J Am Soc Nephrol 5:1106-1111, 1994

14) Spital A: Diuretic-induced hyponatremia. Am J Nephrol 19:447452, 1999

15) Szatalowicz VL, Miller PD, Lacher JW, Gordon JA, Schrier RW: Comparative effect of diuretics on renal water excretion in hyponatraemic oedematous disorders. Clin Sci (Lond) 62:235238, 1982

16) Lenfant C, Chobanian AV, Jones DW, Roccella EJ: Seventh report of the Joint National Committee on the Prevention, Detection, Evaluation, and Treatment of High Blood Pressure (JNC 7): resetting the hypertension sails. Hypertension 41:1178-1179, 2003

17) Williams B, Poulter NR, Brown MJ, et al.: Guidelines for management of hypertension: report of the fourth working party of the British Hypertension Society, 2004-BHS IV. J Hum Hypertens 18:139-185, 2004

18) ALLHAT Officers and Coordinators for the ALLHAT Collaborative Research Group: Major outcomes in high-risk hypertensive patients randomized to angiotensin-converting enzyme inhibitor or calcium channel blocker vs diuretic: The Antihypertensive and Lipid-Lowering Treatment to Prevent Heart Attack Trial (ALLHAT). JAMA 288:2981-2997, 2002

19) Byatt CM, Millard PH, Levin GE: Diuretics and electrolyte disturbances in 1000 consecutive geriatric admissions. J R Soc Med 83:704-708, 1990

20) SHEP Cooperative Research Group: Prevention of stroke by antihypertensive drug treatment in older persons with isolated systolic hypertension. Final results of the Systolic Hypertension in the Elderly Program (SHEP). JAMA 265:3255-3264, 1991

21) Sunderam SG, Mankikar GD: Hyponatraemia in the elderly. Age Ageing 12:77-80, 1983

22) Sharabi Y, Illan R, Kamari Y, et al.: Diuretic-induced hyponatraemia in elderly hypertensive women. J Hum Hypertens 16:631-635, 2002

23) Sonnenblick M, Algur N, Rosin A: Thiazide-induced hyponatremia and vasopressin release. Ann Intern Med 110:751, 1989

24) Clayton JA, Rodgers S, Blakey J, Avery A, Hall IP: Thiazide diuretic prescription and electrolyte abnormalities in primary care. Br J Clin Pharmacol61: 87-95, 2006

25) Walker RM, Brown RS, Stoff JS: Role of renal prostaglandins during antidiuresis and water diuresis in man. Kidney Int 21:365370, 1982

26) Rose BD: New approach to disturbances in the plasma sodium concentration. Am J Med 81:1033-1040, 1986

27) Abramow M, Cogan E: Clinical aspects and pathophysiology of diuretic-induced hyponatremia. Adv Nephrol Necker Hosp 13:128, 1984 
28) Kone B, Gimenez L, Watson AJ: Thiazide-induced hyponatremia. South Med J 79:1456-1457, 1986

29) Klungel OH, de Boer A, Paes AH, Seidell JC, Bakker A: Sex differences in the pharmacological treatment of hypertension: a review of population-based studies. J Hypertens 15:591-600, 1997

30) Ayus JC, Wheeler JM, Arieff AI: Postoperative hyponatremic encephalopathy in menstruant women. Ann Intern Med 117:891897,1992

31) Ghose RR: Plasma arginine vasopressin in hyponatraemic patients receiving diuretics. Postgrad Med J 61:1043-1046, 1985

32) Sonnenblick M, Rosin AJ: Significance of the measurement of uric acid fractional clearance in diuretic induced hyponatraemia. Postgrad Med J 62:449-452, 1986

33) Decaux G, Schlesser M, Coffernils M, et al.: Uric acid, anion gap and urea concentration in the diagnostic approach to hyponatremia. Clin Nephrol 42:102-108, 1994

34) Seldin DW, Eknoyan G, Suki WN, Rector FC, Jr.: Localization of diuretic action from the pattern of water and electrolyte excretion. Ann N Y Acad Sci 139:328-343, 1966

35) Earley LE, Kahn M, Orloff J: The effects of infusions of chlorothiazide on urinary dilution and concentration in the dog. J Clin Invest 40:857-866, 1961

36) Heinemann HO, Demartini FE, Laragh JH: The effect of chlorothiazide on renal excretion of electrolytes and free water. Am J Med 26:853-861, 1959

37) Calesnick B, Brenner SA: An observation of hydrochlorothiazide in diabetes insipidus. JAMA 176:1088-1091, 1961

38) Cesar KR, Magaldi AJ: Thiazide induces water absorption in the inner medullary collecting duct of normal and Brattleboro rats. Am J Physiol 277:F756-760, 1999

39) Kim GH, Lee JW, Oh YK, et al.: Antidiuretic effect of h ydrochlorothiazide in lithium-induced nephrogenic diabetes insipidus is associated with upregulation of aquaporin-2, $\mathrm{Na}-\mathrm{Cl}$ co-transporter, and epithelial sodium channel. J Am Soc Nephrol $15: 2836-2843,2004$ 